\title{
An under-recognized cause for superior vena cava syndrome
}

\author{
Maher M. Nasser, Salman J. Bandeali and Medhat Farwati* \\ Department of Cardiology, Texas Heart Institute, Houston, Texas, USA
}

A 61-year-old African American male with hypertension, endstage renal disease, on haemodialysis since four years. He was referred to cardiology for evaluation of his cardiac status prior to possible renal transplantation. During the time he was on dialysis, he initially had a left subclavian catheter for access. This was removed after an AV fistula was placed in the right arm. Due to thrombosis of the fistula, a right internal jugular tunnelled catheter was inserted and was in place for about three years. His most recent dialysis access was an AV fistula in the left forearm.

Upon examination, patient's face was puffy and plethoric. His superficial neck, chest and abdominal wall veins were markedly

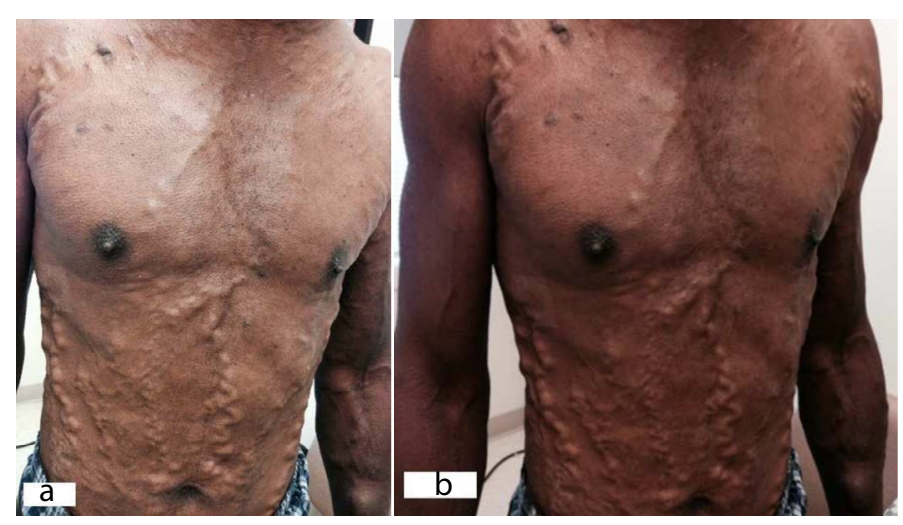

Figure 1. (a) and (b): Physical examination findings of neck, chest and abdomen. The patient showed typical clinical features of a superior cava syndrome with marked distension of his superficial neck, trunk and abdominal veins. Cyanosis of the upper extremities can also be observed. distended. Cyanosis of the upper extremities was observed. Figure 1a $\& \mathrm{~b}$ shows impressive chest and abdominal wall distended veins. A CT scan of the chest showed occluded superior vena cava with extensive collateral vessels throughout the chest region.

The prevalence of superior vena cava syndrome due to long standing venous/ dialysis catheters is increasing [1,2]. However, it still remains an under-recognized and underappreciated cause of the syndrome. Diagnosis is usually made on clinical basis with supportive imaging by CT scan or MRI [1]. Initial treatment of catheter associated SVC syndrome includes removal of the nidus for thrombosis (the catheter) and institution of thrombolytic therapy [1]. Use of long-term anticoagulation therapy is controversial. Endovascular intervention is needed if medical management fails or if there is recurrence of the syndrome $[1,3,4]$.

\section{References}

1. Akoglu H, Yilmaz R, Peynircioglu B, Arici M, Kirkpantur A, et al. (2007) A rare complication of hemodialysis catheters: superior vena cava syndrome. Hemodial Int 11(4): 385-91. [Crossref]

2. Ansari MJ, Syed A, Wongba W, Shaikh Y, Hug S, et al. (2006) Superior vena cava obstruction presenting as a complication of repeated central venous cannulations. Compr Ther 32(3): 189-91. [Crossref]

3. Rice TW, Rodriguez RM, Light RW (2006) The superior vena cava syndrome: clinical characteristics and evolving etiology. Medicine (Baltimore) 85(1): 37-42. [Crossref]

4. Kalra M, Gloviczki P, Andrews JC, Cherry KJ, Jr., Bower TC, et al. (2003) Open surgical and endovascular treatment of superior vena cava syndrome caused by nonmalignant disease. J Vasc Surg 38(2): 215-23. [Crossref]
Copyright: (C)2018 Nasser M. This is an open-access article distributed under the terms of the Creative Commons Attribution License, which permits unrestricted use, distribution, and reproduction in any medium, provided the original author and source are credited.
Correspondence to: Medhat Farwati, 1316 2nd Street NW, Rochester MN, USA, 55901. Tel: 507-202-3088; E-mail: farwati.medhat@mayo.edu.

Received: January 26, 2018; Accepted: February 10, 2018; Published: February 14,2018 